\title{
Experimental Textual-learning Activities for an L2 Italian Initial-literacy Classroom
}

\author{
Castrenze Nigrelli
}

\begin{abstract}
The paper describes some specific textual learning activities developed for an L2 Italian initial literacy classroom and, in particular, for illiterate multilinguals (mostly unaccompanied foreign minors). The activities belong to an experimental proposal. It consists of a specific textual teaching module integrated with a secondlanguage initial literacy course. The aim was to get the learner immediately accustomed to some types of text, that have been chosen to be suitable for his profile and his needs, as well as perfectly integrated with the contexts and vocabulary proposed in the classroom. Because of the minimum level, the texts were mostly discontinuous. Based on the importance of learners' multilingualism, oral ability, and everyday needs, the specific textual activities proposed in the initial literacy classroom have produced significant results, also with important effects on learners' motivation.
\end{abstract}

Keywords - Illiteracy, L2 Italian acquisition, Textual competence.

\section{INTRODUCTION}

ALTHOUGH it is not recent, the problem of migrants' illiteracy is nowadays increasing in Italy because of the high number of migrants that, fleeing from African and Asian countries, reach Italy through a gruelling journey.

Most of that people, both adults and minors, have in fact a low or very low education level; this basically means they are functionally illiterate, or even completely illiterate. A classification of illiterates is that of the Canadian Language Benchmarks 2000: ESL for Literacy Learners, a Canadian document concerning illiterate or poorly educated learners of L2 English. A similar classification has been proposed by Minuz [1].

The problem of the (i)literacy is particularly evident in reference to the category of the so-called "unaccompanied foreign minors" (UFM), that are minors without Italian citizen and without adults who have legal responsibility. The above minors have a sociolinguistically quite particular profile: they mostly have a very low, or zero, education level and, together, a surprising multilingual competence. In fact, multilingualism is not necessary linked to the education level (see [2]). For more details about UFMs, see [3].

A competence in the language of the host country represents the main instrument for social integration. The illiterates have a linguistic competence, also including their L1, that is

Castrenze Nigrelli is with the University of Palermo - 90128 Palermo ITALY. basically limited to orality. The limited familiarity with written texts has strong repercussions on the lack of meta-textual and meta-linguistic reflection, and this has in turn negative consequences on the second-language acquisition process (see [4]-[5]). The difficulties of low educated and illiterate learners in learning a second-language represent a factor of risk of exclusion (see [6]): in fact, the complexity of the present-day society, with its so-called urban linguistic landscape [7], continuously requires decoding activity. On the contrary, learning to read and write gives learner a tool to actively participate in the social life of the community in which he is located, changing somehow the whole society as well [8].

\section{II.LEARNING LITERACY IN A SECOND LANGUAGE: A HARD PATHWAY}

UFM learners' multilingual ability is far from being marginal: it represents both a strong element of identity for the purposes of full integration into society, and a precious resource with respect to the learning pathway. In fact, within a classroom, the multilingual baggage of UFMs becomes a concrete support to the educational and didactic experience: it is not in fact rare for a learner to be able to come to the aid of another thanks to a language that is not his mother tongue.

However, learning literacy in a second language is a hard and complex objective: the learner must both learn another language, and learn to read and to write for the first time and transform his knowledge into useful and expendable skills. In a similar way, teaching literacy in a second language classroom consists in teaching not just how to read and write, but also how to use these tools independently, therefore guiding learners to build a more solid relationship with the host country.

From the perspective of the communicative approach, which focuses on the learner, Minuz [1] claims that the success of a teaching-learning pathway depends on a crucial factor: the compliance of the course to the motivations, needs and expectations of the participants. In particular, the development of motivation in illiterate foreign learners strongly depends on the awareness that the effort required in the literacy classroom will have a concrete usefulness in everyday world. Also for this reason, it is essential the role of an always recognizable context that acts as a linguistic container.

\section{THE ACTIVITY AT THE UNIVERSITY OF PALERMO}

Models of integration of all the so-called "fragile" users (i.e. 
UFMs, asylum seekers, women) in its own classes of L2 Italian have been developed at the University of Palermo.

By implementing an agreement with the communities, that responsively follow the students' learning pathway, it has been decided to include the UFMs within classes consisting of students with an ordinary or higher level of education (often university students from other countries), working alongside tutors who can serve as a reinforcement for them along the way. Such language courses mostly follow the communicative teaching approach, joined by the affective-humanistic perspective, looking therefore at the learner and his specific communication needs, as well as emotional and psychological aspects linked to learning.

The UFM illiterates, instead, start by making a dedicated literacy pathway, divided into three levels (initial, intermediate, advanced) to whose respective classes the illiterates are assigned based on their level of mastery of reading-writing, and successively - only at the conclusion of this pathway - they are included in the ordinary classes.

In the multiethnic, multicultural, and multilingual microcosm of these mixed classes, language learning and social integration not only coexist simultaneously, but they favor each other.

Furthermore, multilingualism and oral ability in the target language of fragile learners constitute precious resources with respect to both the learning and the integration pathway. A core issue and starting point of the literacy pathway is the oral competence of the learner's L2. In fact, if the learner has a good oral competence in the target language, it will be easier and faster to set up a read-write pathway starting from words or phrases to be analyzed on an alphabetical level. If not, it is all the more difficult, since there is no reference to the illiterate learner, making it a priority to focus on the development of orality, of oral communicative competence, in terms of both reception and production.

Therefore, the pathway of reading-writing cannot ignore the oral competence in the target language. In order to be able to propose an alphabetical analysis with ease, the word (or sentence) must have a meaning and therefore there must always be a recognizable context to keep in mind, which acts as a frame of reference, as a linguistic container, for the learner. Therefore, to keep classroom activities always linked to the context of external reality is a fundamental step because it motivates the learner and accelerates the process of readingwriting. This provides the learner with a meaningful support, that is useful to the process of reading and writing, and shows him how useful it would be in the real world.

The class thus is increasingly perceived as a safe place in which to be able to collaborate with more ease and take the initiative. There is another reason, far from being secondary, which is that it is good to focus on the oral dimension first. The process of learning basic oral skills is much shorter than the primary skills of reading-writing, so it is right to provide the learner with a basic oral knowledge, together with the pathway of reading-writing in order to be able to navigate themselves in the real world by dealing with the communicative tasks of his daily life, and starting to have and use the first means for social inclusion and promotion.

Going deeper, the proposed literacy pathway is divided into two phases: the phase of orality and the literacy phase. These two moments are intimately interconnected and mutually indispensable. The first phase, that is aimed at soliciting the orality of the learner, is divided into three sub-phases: presentation, manipulation and production. In the presentation, the teacher uses objects or images to elicit, and eventually present, the most suitable word to describe the object or situation shown. To make sense, words must be firmly contextualized and the semantic contexts or areas must be related to the everyday reality of the learner. In the manipulation sub-phase, the teacher proposes a series of activities that lead the learner to become familiar with the alphabetical sequence of the word: the images are now accompanied by the word in written form and the learner is called to place the images in the correct reference context. This brings the learner to master the lexical area relating to the words already learnt and to deepen their semantic understanding, without therefore limiting themselves to oral reproduction. In the production sub-phase, the learner is called to use the just learned and manipulated words within free or controlled communication routines. The aim is to reuse the vocabulary learned in a precise communicative context. In this step it is also possible to think of an outside activity, placing the learners in real contexts (for example, taking them to buy a pen), or staying in the protected environment of the class and guiding learners into a simulated activity (for example, a role play).

After the phase of orality, in the literacy phase the learner is gradually put in contact with the written word, and the teacher guides him through an analysis starting from a chosen basic form. At the University of Palermo an analytical-synthetic method has been adopted, whose procedure foresees to start from the word, analyzed semantically, then to move on to the analysis of the syllable, chosen as the base form, and finally to return again to the word, now also structurally analyzed.

However, the teacher will have to dwell on the semantics of the word as long as it takes for the learner to learn its meaning, and only then he can focus his attention on the analysis of the syllable. Actually, in the classroom it is often necessary shorten the time. In any case, at least at the level of initial literacy, it is good to dedicate more than half of the lesson to orality.

In the acquisition of reading and writing skills, one of the most important strategies is the recognition of word boundaries. The learners usually recognize the word as a unit, first through its length or position, then through the analysis of graphemes, and finally by spelling, i.e. by reading the word automatically. Illiterates seem to have greater difficulty than literates in considering the word as an autonomous entity with boundaries; the language appears to them as means of communication rather than a system consisting of elements 
divisible into smaller units. Illiteracy can have repercussions on the perception of oral language, so that the difference between the learner's production and the teacher's corrective feedback, or the linguistic input received from outside, may not be noticed by the learner, inevitably causing fossilization. The corrective feedback of the teacher must therefore not focus only on small linguistic units, such as syllables, but also focus on prosodic aspects.

As for a syllabus for illiterates, important points of reference are the syllabus of Borri et al. [9], a guide to a course from literacy to A1 level, as well as the above mentioned Canadian Language Benchmarks 2000: ESL for Literacy Learners.

As said, at the University of Palermo has been adopted a three-level didactic intervention for illiterates. Based on the results of a special entrance test, the illiterate UFMs are assigned, to one of the following levels:

1) initial literacy: exercises in pre-literacy and guidance on writing on paper, and beginning of a pathway of association of sound to the written word;

2) intermediate literacy: in-depth analysis of the alphabetical sequence (even complex sounds) and progressive approach to the written comprehension of simple sentences;

3) advanced literacy: gradual starting to read short, simple, and useful texts.

The above pathway ideally accompanies the UFM up to access to the A1 level ordinary classes (level following the advanced literacy level).

Initial literacy classes, mostly composed of UFMs, basically revolve around the word as a starting point for a first semantic approach and, only then, as a support for a more analytical reflection. Taking into account the difficulty of abstraction and categorization that characterizes the illiterates, the didactic model provides for meta-linguistic reflection (i.e. gender and number distinction) in all three classes of literacy, as an essential resource for the purposes of communicative competence. After having carried out a preliminary work that brings the learner to frame the word in its entirety, the teacher will prudently try to guide him towards the awareness that words are made up of smaller elements, bearing meaning, without using abstract categories. For the first level of literacy, it is essential to name the things that surround the learner and anchor them firmly to the contexts through a gradual transition from image to word in written form. To be effective, analytical reflection on the word must be based on something already known. Since the image plays a key role in learning basic vocabulary and therefore in oral competence, it is advisable to linger on the image as long as necessary: for example, leaving an image permanently affixed to the wall of the classroom makes the classroom itself become an educational kit, always available to the learner (and the teacher).

In some ways, the word may seem to be the horizon within which this first literacy level is defined. If this is true for the literacy phase, the same cannot be said with regards to the phase of orality. In fact, in the production sub-phase, the learner begins to become familiar with the upper levels of the sentence and the text, albeit to a minimum extent and not in an analytical and fully aware manner.

The textual competence is part of the more general communicative competence, and concerns the ability to know how to identify the information conveyed by the text, as well as the way in which it is conveyed. The textual competence is therefore not only a question of knowing how to grasp the meaning (not only in its entirety) of the text, but also to be aware of its logical and formal organization, thus implying the ability to make inferences and to grasp the elements of cohesion and coherence.

In a learning pathway it is important to work on textual competence because through it cognitive mechanisms are developed that have important implications both on the learning of a second language, and on the reinforcement of instrumental reading and writing skills. The texts also serve to propose new contexts which stimulate and motivate the learner if drawn from everyday experience. Moreover, outside the classroom, the urban context offers (when it does not impose) continuous textual stimuli.

Within the literacy pathway described so far, working on texts is normally destined to the intermediate literacy level and, even more, to the advanced literacy level, whose main objective is the full functional literacy. However, textual activities has also tested in the initial literacy class, as an integrated module, despite the main objective of this course is essentially limited to instrumental literacy.

Since the main objective of a initial literacy course is essentially limited to instrumental literacy, proposing to work on textuality in a class of this level, moreover composed of UFM, may seem a stretch. Textuality with the illiterate: almost an oxymoron. In fact, the intent was to understand if, and to what extent, it was possible to propose a textual teaching module integrated with the regular initial-literacy course. The aim was to get the learner immediately accustomed to some types of text, that have been chosen to be suitable for his profile and needs, and to be perfectly integrated with the contexts and vocabulary proposed in the classroom. Because of the minimum level, it was mostly discontinuous texts. The main textual activities proposed in the classroom are shown in the next Section.

\section{TEXTUAL ACTIVITIES FOR THE INITIAL LITERACY LEVEL}

In order to be sure that the textual activity is useful, it has been almost always proposed near the end of the orality phase, together with the production sub-phase. Once the new vocabulary has been presented (presentation sub-phase) and once it has been framed at a semantic level within a context (manipulation sub-phase), some production activities have been proposed. These would favor the practice within communicative routines and were usually role play activities. The teacher mimics a situation and invites the learners to elicit some simple communicative strings that can be hypothesized starting from teacher's actions. Once learners have reached a 
series of acceptable strings, the teacher has them fixed to the learners, who will then try to recreate the scene in pairs. At this point, the teacher inserts the textual element, very often introducing authentic or adapted materials that arouse the curiosity and the interest of the class. As examples of textual elements a receipt and a label of a shirt have been employed. These are in fact two discontinuous texts, classifiable as descriptive/regulatory, very common in everyday life. These texts were proposed in two different role plays: one set in the supermarket and the other in a clothing store. The guided oral productions, related to both role plays, are linked to the vocabulary of food and clothing, and, at the same time, the communicative strings suggested by the mimed situation are also based on the textual element, thanks to the presence in the classroom of the real object. The focus on the textual element is almost always presented just before moving on to the role play, or contextually to it, during the string elicitation phase. Starting from the real object, the teacher proposes, by the blackboard and/or a worksheet, to focus the learners' attention on salient textual elements in relation to the type of text and its function. For example, on the receipt, it will be highlighted the importance of the date, the indication of the price and the change. On the shirt label, it will be highlighted the indication of size, color, price, and washing instructions. This type of activity arouses the interest and motivation of the learner, since it is clearly coherent with the real context, with frequent and plausible communicative situations and with his communication needs.

In other cases, the textual activity is disconnected from a communicative situation like the one suggested by the role play, but connected the same to the real and daily context of the learners' needs. An example is the case with the coffee machine, which presents a number of textual elements. The activity takes place outside the classroom. After the previous lessons in which the vocabulary of food and drink has been proposed, the teacher guides the students to the use of the coffee machine, soliciting their attention on the text - also in this case, discontinuous and descriptive/regulatory - and, in particular, on the correspondence between number and product, between button and function.

A further example of a textual proposal is the daily agenda that represents a particularly interesting activity, because it can go beyond the planned textual objectives and the general expectations of the teachers. Such activity takes place at the end of the lesson. The basic idea is to accustom the learners to compiling an empty handmade notebook, as if it is a daily diary, on which to write down, with the help of the teacher, the learned words under the heading "Oggi ho imparato..." ("Today I have learned...").

Before completing the agenda, the teacher manages a brief moment of elicitation in plenum, which is then followed by the transcription of each one individually. This activity has the textual function of making the learner approach a blank page, that - in a guided manner - he would fill with various elements: the date at the top, the lines on which to write within the margins, and finally the words. This represents also a daily opportunity to train writing, with particular attention to isolating words, identifying their boundaries. Day after day, the empty notebook takes the form of a real agenda, that can be employed as a textbook.

This activity develops the learners' autonomy: over time, in fact, it is the students who decided to write what they want, including words learned elsewhere. In addition, by this activity the teacher educates the learners to care for the book and, in general, for the scholastic equipment. The students also initiate an identification mechanism, since, at the suggestion of the teacher, each of them could personalize the cover with a drawing or a name. A further important aspect is the motivation that arises in the learner when focusing and putting down in writing what he has learned in class, becoming aware of a progressive advancement in his own knowledge and skill.

Finally, the time to complete the agenda, always placed at the end of each lesson, gradually becomes an essential moment of relaxation that creates a comforting routine. This latter is an indispensable element for this type of learners who are not used to being in a school environment and it has a very positive emotional impact.

\section{REFERENCES}

[1] Minuz F. (2005), Italiano L2 e alfabetizzazione in età adulta, Roma, Carocci

[2] Tarone B., Bigelow M., (2011), A Research agenda for second language acquisition, in: Vinogradov P., Bigelow M. (Eds.), Low Educated Second Language and Literacy Acquisition - Proceedings of the 7th Symposium, Minneapolis, Minnesota, USA, 5-26.

[3] Barone L. (2016), L'accoglienza dei minori stranieri non accompagnati. Tra norma giuridica e agire sociale, Key Editore.

[4] Luria A. R. (1976), Cognitive development: Its cultural and social foundations, Cambridge, Harvard university press.

[5] Ong W. (1982), Orality and Literacy, London-New York, Methuen. https://doi.org/10.4324/9780203328064

[6] Demetrio D., Moroni F. (1980), Alfabetizzazione degli adulti: teoria, programmazione, metodi, Roma, Editrice sindacale italiana.

[7] Landry R., Bourhis R. Y. (1997), Journal of Language and Social Psychology 16, 1, 23-49. https://doi.org/10.1177/0261927X970161002

[8] Watson J. A. (2011), Cautionary tales of LESLLA Students in the High School Classroom. In P. Vinogradov, M. Bigelow (Eds.), Low Educated Second Language and Literacy Acquisition - Proceedings of the 7th Symposium, Minneapolis, Minnesota, USA, pp. 203-234.

[9] Borri E., Minuz F., Rocca L., Sola C. (2014), Italiano L2 in contesti migratori. Sillabo e descrittori dall'alfabetizzazione all'A1, Torino, Loescher. 